\title{
MUSIC COMPOSITION BY ONOMATOPOEIA
}

\author{
Toshiyuki Masui \\ Sony Computer Science Laboratories, Inc. \\ 3-14-13 Higashi-Gotanda \\ Shinagawa 141-0022, Japan \\ masui@acm.org
}

\begin{abstract}
We introduce a simple music notation system based on onomatopoeia. Although many text-based music notation systems have been proposed, most of them are cryptic and much more difficult to understand than standard graphical musical scores. Our music notation system, called the Sutoton notation, is based on onomatopoeia and note names which are easily pronounceable by humans with no extra training. Although being simple, Sutoton notation has been used in a variety of systems and loved by many hobbyists.
\end{abstract}

Keywords: Computer music, music markup language, MML, desktop music, DTM, Sutoton notation

\section{Introduction}

Many people are enjoying music on personal computers today. PC-based music systems are sometimes called as DTM (DeskTop Music) systems, and a variety of hardware and software products are now available.

Most of the current DTM systems are based on graphical user interfaces (GUIs), and users can edit notes and control various attributes of music graphically on the screen with direct manipulation interfaces. Although commercial GUI-based DTM systems are sophisticated and easy to use, they are sometimes too complicated for casual users, and they are designed for interactive use and not easy to control from other programs.

On the other hand, Text-based music description languages have been used to represent scores from the beginning of the research history of computer music. Even today, text-based representations are useful in many cases, since texts are easily handled by text editors and other programs. Text-based music description languages are also good for resource-poor systems like old personal computers and small mobile devices.

A number of text-based music description languages have been proposed and used[2]. Many of the languages were developed for research, but vari-

The original version of this chapter was revised: The copyright line was incorrect. This has been corrected. The Erratum to this chapter is available at DOI: 10.1007/978-0-387-35660-0_65 
ous new text-based languages are widely used for DTM hobbyists these days. Text-based music description languages for DTM are sometimes called as Music Markup Languages (MMLs). Many people prefer using MMLs for music composition, because they can use their favorite text editors for handling music.

Although MMLs are convenient to handle, notations of MMLs tend to be complicated and difficult to understand. In many MMLs, notes are represented by numbers or symbols, and it is usually much harder to read than reading standard graphical music scores. Figure 1 shows an example score written in an existing MML. It is very hard to read, maybe even for the person who wrote it.

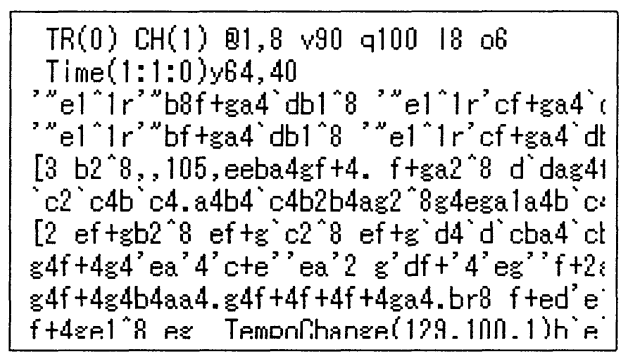

Figure 1. Cryptic score using a MML.

We propose using onomatopoeia and note names for MML. Instead of using symbols like "a" and "b" used in Figure 1, we use pseudo words which sound similar to the real sounds and notes. For example, we use words like "ding" and "ping" for percussive instruments, and use "do" and "re" for representing notes, so that we can just read the notation and understand the sound easily. We call this the Sutoton notation ${ }^{1}$, and in this paper, we introduce how Sutoton notation can be used for simple music composition.

\section{Sutoton Notation}

Sutoton notation is a human-pronounceable text string which represents musical notes and percussive sounds. A note or a hitting sound is represented by a single word whose pronunciation is similar to the real sound. For example, "bang" and "dong" can be used as a word for representing a percussive sound.

\subsection{Examples of Sutoton notations}

Figure 2 shows a simple example of the Sutoton notation and corresponding musical score.

Durations of notes are represented by their pronunciations. Double vowels and extra consonants can be used for longer notes. 


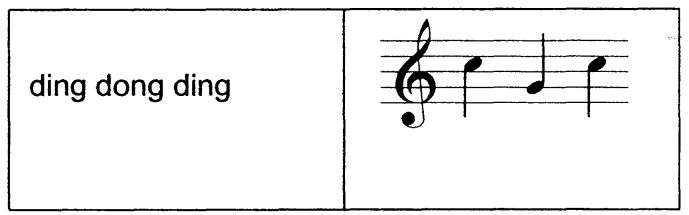

Figure 2. Simple Sutoton notation.

\begin{tabular}{|l|l|}
\hline $\begin{array}{l}\text { di di di ding } \\
\text { (ダダダダン) }\end{array}$ \\
\hline $\begin{array}{l}\text { soo so fa mi } \\
\text { ソーソファミ) }\end{array}$
\end{tabular}

Figure 3. Long and short notes.

Here, "soo" represents a long "so"(G), and should be pronounced as "sooh" in standard English pronunciation". The same notes in Japanese are also shown in Figure 3.「ダ」 and「ダン」 are Japanese onomatopoeias for purcussive sounds, 「ソ」 represents "so", 「ー」 represents a double vowel, and so on.

Rests are represented by double consonants. 「ッ」 denotes a double consonant in Japanese ${ }^{3}$.

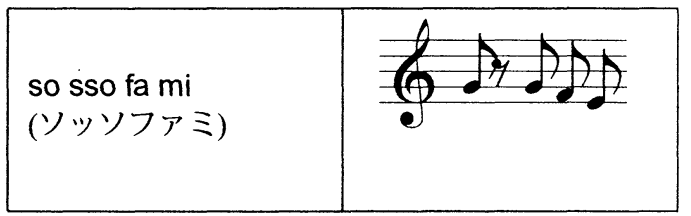

Figure 4. Rest representation.

With these simple rules, "Happy birthday to you" can be represented in Sutoton notation like below:

doddo reee dooo faaa miiiiii

(ドッドレーードーーファーーミーーーーー)

doddo reee dooo sooo faaaaaa

(ドッドレーードーーソーーファーーーーー) 
And R. Wagner's Bridal March can be represented like below:

\begin{tabular}{|l|}
\hline dooo faffa faaaaaa \\
(ドーーファッファファー-ーー \\
dooo sommi faaaaaa \\
(ドー-ソッミファー--ー- $)$
\end{tabular}

\section{Sutoton-based Systems}

Since Sutoton notation is so simple and easy to understand, various Sutotonbased systems have been developed by the author and other people who are interested in easy music composition.

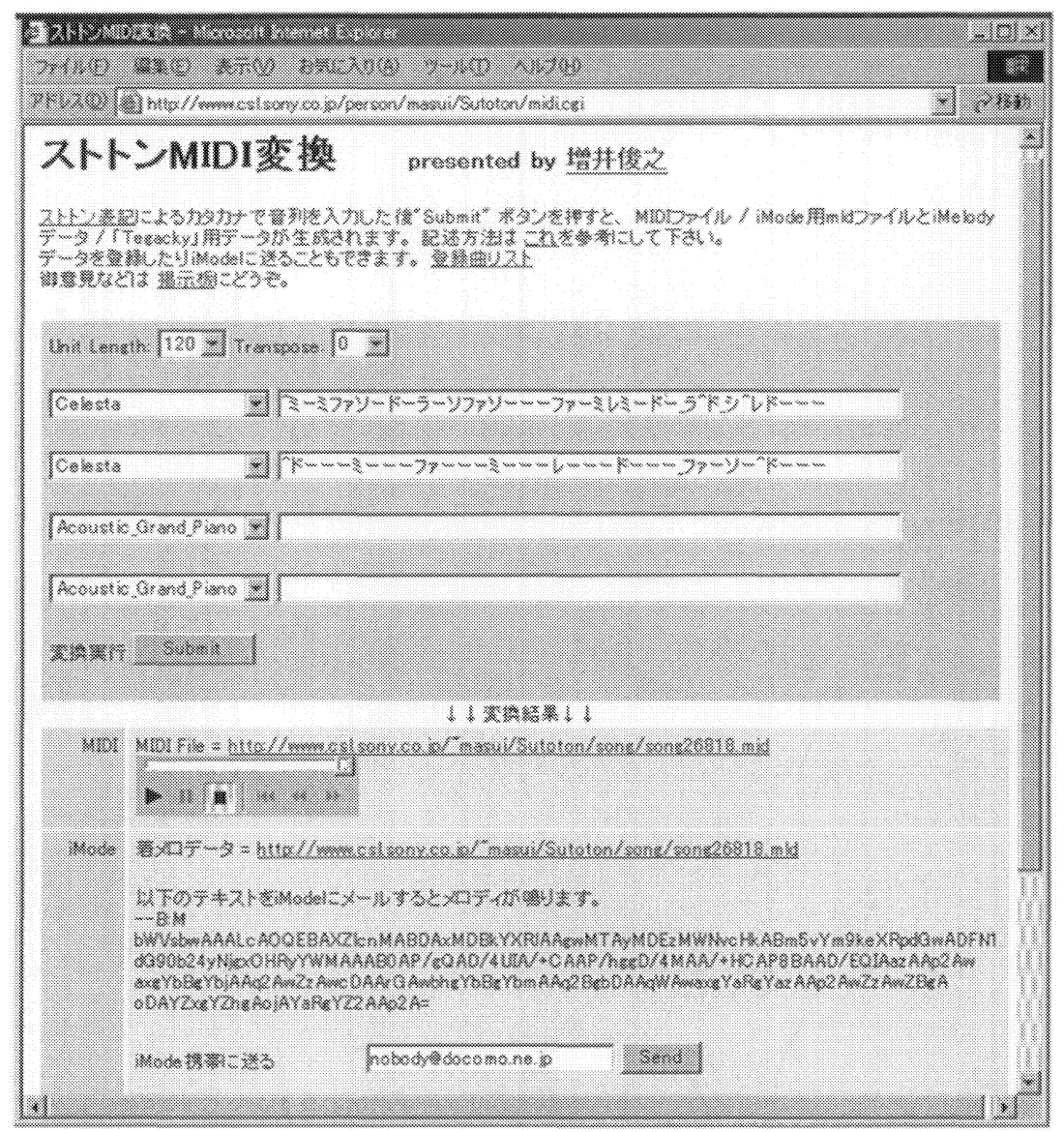

Figure 5. Sutoton Web 


\subsection{Sutoton Web}

We introduced Sutoton notation in May 1999, and our Sutoton Web has been open to the public since then. On the Sutton Web page, users can enter strings in Sutoton notations and hear the music on the browser by converting it to MIDI. Users can also register their score on the Web, or send the data to various cellular phones via e-mail ${ }^{4}$. When people receive the data on their cellular phones, they can hear the sound and register it as their own call-receiving sound.

\subsection{Sutoton-based DTM systems}

Sakura is a text-based DTM system on Microsoft Windows, developed by Mineaki Yamamoto ${ }^{5}$. A special MML shown in Figure 1 was originally used in Sakura, but after adopting Sutoton notation as the alternative, it became very popular and won the Online Software Award ${ }^{6}$ of 2001 sponsored by Internet Association Japan.

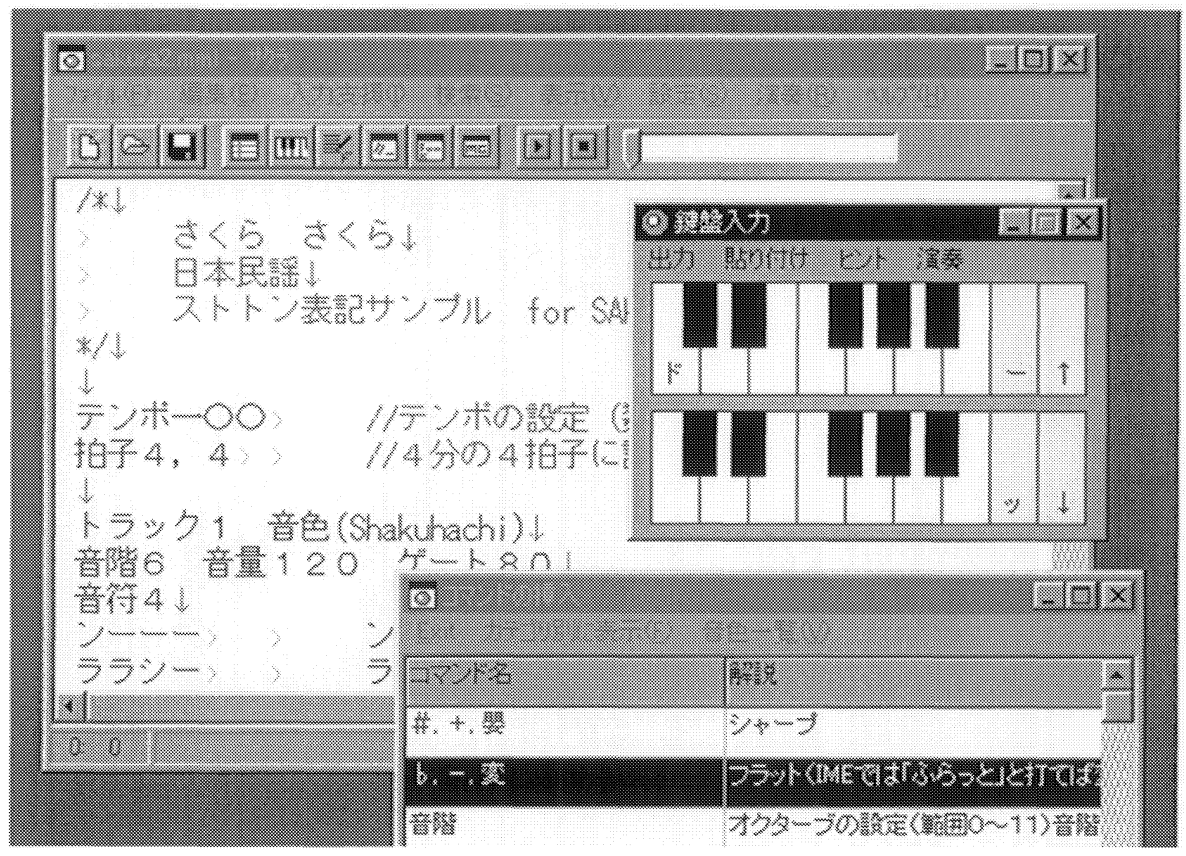

Figure 6. Sakura Music Editor. 


\subsection{Sutoton on mobile devices}

Since Sutoton notation is very simple, Sutoton-based texts can easily be edited and handled on devices with small screen and low CPU power. Figure 7 shows a Palm program interpreting the Sutoton notation of the Wedding March. The plugin program, called $\mathrm{MMLDD}^{7}$, can interpret selected text in any Palm application as Sutoton notation and plays the sound. Unfortunately Palm devices can play only one note at a time and composition using Palm is not really fun, but we can see that Sutoton notation is promising for small devices.

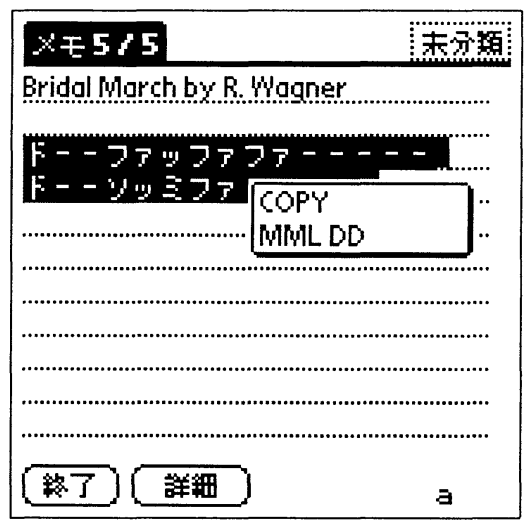

Figure 7. Using MMMLD on a Palm.

\section{Using Sutoton Notation from Programming Languages}

Since Sutoton notation is based on a simple text string, it can be used in any programming language that can handle character strings. A simple Sutoton library for each language can be used for playing notes.

$$
\begin{aligned}
& \text { require 'sutoton.pl'; } \\
& \text { \&play("ドレミファミレド"); }
\end{aligned}
$$

Figure 8. Using Sutoton notation from Perl.

Figure 8 shows how Sutoton library can be used in Perl. In the Sutoton Web page shown in Figure 5, a CGI program converts the given Sutoton notation into a Perl program like above, and the notation is converted to standard MIDI format. 
Most of the DTM systems only handle static data given by the user, but music data can be used in wider range of applications by dynamically creating Sutoton notation.

\subsection{Music generation}

Sutoton notation can be used in algorithmic composition systems. The Perl program shown in Figure 9 generates 1000 random notes.

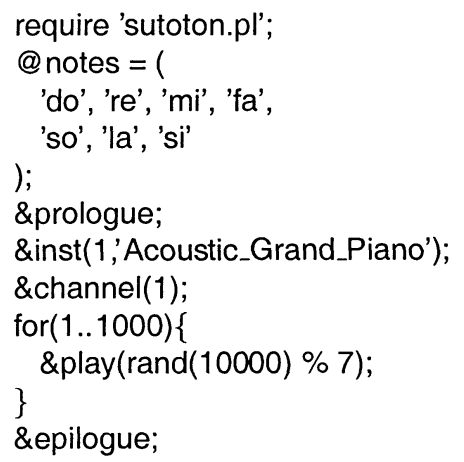

Figure 9. Rarndom note generator.

\subsection{Generating Earcons}

Blattner proposed the use of Earcons[1], which are sound patterns that tell users the status and the event of the underlying system. In the program shown in Figure 10, a Sutoton notation is used for creating an Earcon which tells the user about the type of the error.

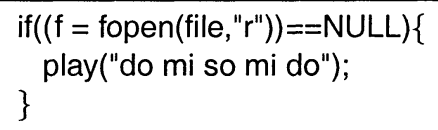

Figure 10. Generating an Earcon using Sutoton Notation.

\section{User Evaluations}

We have not performed any user test on Sutoton notation, but we can see the reputation of it from various information found on the Web. 
Sutoton notation and Sutoton Web have been available since May 1999. About 27,000 people have visited the page since then, and more than 100 songs have been registered by the visitors.

It is difficult to count the number of people using Sakura, but we can find many Web pages which mention Sakura and Sutoton notations, and we can also find many songs written in Sutoton notation. Usually we find favorable comments on such pages.

\section{Conclusions}

We have introduced a simple text-based music notation system called Sutoton notation, which is based on onomatopoeia and easily pronounceable note names. Sutoton notations are used in various systems on the Web and on various machines, and widely used by casual computer music lovers.

\section{Notes}

1. "Sutoton" is a Japanese onomatopoeia for percussive sounds.

2. Sutoton notation was originally developed for Japanese language, and English readers might feel that the pronunciation is not intuitive.

3. Double consonant( ) is very popular in Japanese pronunciation, but it is said to be one of the few sounds which is difficult for English-speaking people to distinguish and pronounce.

4. Encoded text shown at the bottom of Figure 5 is sent to the cellular phone via e-mail.

5. Sakura is available at http://www.text2music.com/tools/sakura/sakura.htm

6. http://www.iajapan.org/osp/

7. MMLDD was developed by Masakazu Matsumoto and available at http://www.chem.nagoyau.ac.jp/matto/Palm/

\section{References}

[1] Meera M. Blattner, D. A. Sumikawa, and R. M. Greenberg. Earcons and icons: Their structure and common design principles. Human-Computer Interaction, 4(1):11-44, 1989.

[2] Curtis Roads. The Computer Music Tutorial. MIT Press, February 1996. 


\section{SOCIOLOGY AND PSYCHOLOGY OF ENTERTAINMENT}

